\title{
Comparative analysis of cod and herring production dynamics across 13 northern hemisphere marine ecosystems
}

\author{
Kirstin K. Holsman ${ }^{1, *}$, Timothy Essington ${ }^{2}$, Thomas J. Miller ${ }^{3}$, \\ Mariano Koen-Alonso ${ }^{4}$, William J. Stockhausen ${ }^{5}$

\begin{abstract}
${ }^{1}$ Joint Institute for the Study of the Atmosphere and Ocean, University of Washington, Seattle, Washington 98195-5672, USA
${ }^{2}$ School of Aquatic and Fishery Sciences, University of Washington, Seattle, Washington 98195-5020, USA

${ }^{3}$ Chesapeake Biological Laboratory, University of Maryland Center for Environmental Science, Solomons, Maryland 20688, USA

${ }^{4}$ Northwest Atlantic Fisheries Centre, Fisheries and Oceans Canada, St John's, Newfoundland and Labrador A1C 5X1, Canada ${ }^{5}$ Alaska Fisheries Science Center, NOAA Fisheries, Seattle, Washington 98115, USA
\end{abstract}

\begin{abstract}
We conducted a comparative ecosystem analysis to understand environmental and biological drivers of production dynamics of 2 common species groups, cod (Gadus morhua and G. macrocephalus) and herring (Clupea harengus and C. pallasii), across 13 large marine ecosystems. For all 4 species, we fit a hierarchy of nested surplus production models with terms for trophodynamic and biophysical covariates; models were then compared using an informationtheoretic framework. Across ecosystems, models including terms for biophysical covariates exhibited stronger fits to the data and were often included in the top set of selected models. However, the numerical effects of covariates differed among systems and species. For example, surplus production in several ecosystems was significantly affected by sea surface temperature, but to differing degrees (i.e. direction and magnitude of effect). Similarly, surplus production of cod was positively associated with herring biomass in 4 of the ecosystems examined, whereas negative trophodynamic interactions alluded to complex cultivation-depensation food-web dynamics in 5 other systems. Importantly, no single covariate emerged as the most important predictor of surplus production nor were biological reference points from models with covariates always more conservative than those without covariates. This suggests that inclusion of trophodynamic and biophysical covariates in simple production models has the potential to increase model fit, but the relative benefit will be stronger for systems and species where trophodynamic and biophysical processes are tightly coupled to species productivity.
\end{abstract}

KEY WORDS: Cod · Herring · Surplus production - Fisheries management - Trophic dynamics · Biological reference points $\cdot$ Environmental factors $\cdot$ Maximum sustainable yield $\cdot$ MSY

\section{INTRODUCTION}

Ecosystem-based approaches have been promoted as a way to improve fisheries assessment and management (Pikitch et al. 2004, US Commission on Ocean Policy 2004, Link 2010). There are multiple facets and goals of the ecosystem-based approach, but a central feature is a holistic perspective on fisheries productivity that considers multiple controls beyond fishing mortality and stock size (Walters \& Martell 2004, Hollowed et al. 2011). One potential benefit of this approach is improved estimates of both biological reference points (Overholtz et al. 2008, Tyrrell et al. 2011) and of population trajectories under various future management and climatic scenarios. For example, consideration of trophodynamic interactions in both stock assessments and harvest policies might improve assessment accuracy and 
identify trade-offs that emerge between fisheries that target multiple species in a food web (Link 2010, Constable 2011, Smith et al. 2011).

Although the importance of biophysical and trophodynamic drivers of fisheries production dynamics are widely acknowledged (e.g. Mantua et al. 1997, Lehodey et al. 2006, Baum \& Worm 2009), identifying and ranking the relative influence of these drivers on production rates is challenging. Often covariates of fisheries production dynamics are determined through a correlation analysis of data from multiple time series. Yet, survey and biophysical time-series data are frequently autocorrelated, so that spurious relationships between production dynamics and environmental variables are not uncommon. For example, Leggett et al. (1984) analyzed data from 1966 to 1978 for capelin Mallotus villosus and found a strong correlation between recruitment, sea surface temperature, and the frequency of onshore winds during larval emergence from spawning beaches. Yet, when Carscadden et al. (2000) updated the original analysis with additional years of data, temperature was no longer a useful predictor of recruitment. These authors speculated that the original correlation was spurious rather than causative. In a broad review of such relationships, Myers (1998) noted that recruitment correlations become particularly unreliable when time series are short relative to generation times. Other authors have since demonstrated additional challenges inherent in using correlative approaches to evaluate processes that may act synergistically to regulate production dynamics (Hunt et al. 2002, Hunt \& McKinnell 2006).

The comparative approach has been identified as a promising tool to provide ecosystem-scale scientific advice for fisheries (Megrey et al. 2009, Murawski et al. 2009). We suggest that the comparative approach is also helpful in assessing the importance of ecological covariates in predicting production of fisheries stocks. By assessing covariates of fisheries production across multiple ecosystems that have unique histories of environmental forcing and food web dynamics, it may be possible to identify covariates that consistently predict production levels and thereby diminish the likelihood of drawing spurious correlations. Indeed, Myers (1998) recommended a comparative approach in his review of correlative studies of environmental controls of recruitment. More generally, such analyses offer the potential to distinguish covariates that regulate production in many different ecosystems as opposed to the system-specific effect of individual covariates. Additionally, a comparative approach can also reveal how mean levels of produc- tivity vary across ecosystems and thereby detect controls of productivity that might be concealed in analysis of data from a single ecosystem (Perry \& Schweigert 2008).

As a part of a larger collaborative project to compare the dynamics of marine ecosystems (see Gaichas et al. 2012, this Theme Section), we assembled time series data on biomasses and harvest of multiple species in 13 different northern temperate ecosystems (see Fig. 2 in Link et al. 2012, this Theme Section). The overall goal of the project was to quantify the relative importance of biophysical (environmental), trophodynamic and exploitative processes on production. To maximize the strength of the comparative approach, we apply a simple production model to population and harvest biomass data for cod and herring species, which were present in most of the 13 northern ecosystems. These 2 species groups have traditionally supported culturally and economically important fisheries (Kurlansky 1997) and have also long been the focus of efforts to relate population dynamics to environmental conditions (e.g. Hjort 1914, Sinclair \& Tremblay 1984). As a result, there are ample data sources from a diverse array of marine fishery ecosystems on which to base comparative analyses. The surplus production modeling framework was chosen because the notion of surplus production is fundamental to both single species and ecosystem-based approaches (Schnute \& Richards 2002, Walters et al. 2008). Moreover, despite their simplicity, surplus production models can outperform more complicated age-structured models (NRC 1998). Here we use a surplus production modeling framework to ask: (1) how do average surplus production levels relate to ecosystem scale properties such as temperature, (2) do particular biophysical or trophodynamic variables consistently predict production dynamics across ecosystems, and (3) are biological reference points (e.g. maximum sustainable yield [MSY]) for each species group similar across ecosystems?

\section{MATERIALS AND METHODS}

We evaluated patterns in biomass and annual surplus production for Atlantic and Pacific cod (Gadus morhua and G. macrocephalus, respectively) and Atlantic and Pacific herring (Clupea harengus and C. pallasii, respectively) from 13 high-latitude ecosystems that varied in size and ecosystem structure (Table 1). Although we recognize that there are specific differences between the species pairs, we argue that each occupy similar niches in the individual 
Table 1. Ecosystem abbreviation and area, and the number $(n)$ and range of years of cod and herring biomassdata included in each ecosystem- and species-specific analysis

\begin{tabular}{|lcccccccc}
\hline Ecosystem & \multirow{2}{*}{ Abbreviation } & Area & \multicolumn{2}{c}{ Cod } & & \multicolumn{2}{c}{ Herring } & Data source \\
& & $\left(10^{3} \mathrm{~km}^{2}\right)$ & $n$ & Years & $n$ & Years & \\
\hline Baltic Sea & BALT & 211.1 & 34 & $1974-2007$ & 34 & $1974-2007$ & Stock assessment \\
Barents Sea & BS & 525.3 & 63 & $1946-2008$ & 59 & $1950-2008$ & Stock assessment \\
Eastern Bering Sea & EBS & 430.8 & 32 & $1977-2008$ & 29 & $1978-2006$ & Stock assessment \\
Eastern Scotian Shelf & ESS & 113.7 & 38 & $1970-2007$ & & & q-corrected biomass \\
Georges Bank & GB & 42.2 & 44 & $1963-2006$ & 41 & $1967-2007$ & q-corrected biomass \\
Gulf of Alaska & GoA & 238.4 & 32 & $1977-2008$ & 29 & $1980-2008$ & Minimum swept area \\
Gulf of Maine & GoM & 76.5 & 44 & $1963-2006$ & 41 & $1967-2007$ & q-corrected biomass \\
Hecate Strait & HS & 23.5 & 25 & $1984-2008$ & 59 & $1951-2009$ & q-corrected biomass \\
Newfoundland and Labrador & NL & 388.2 & 27 & $1981-2007$ & & & Minimum swept area \\
North Sea & NORT & 609.7 & 44 & $1963-2006$ & 44 & $1963-2006$ & Stock assessment \\
Norwegian Sea & NS & 728.3 & & & & 59 & $1950-2008$ & Stock assessment \\
Southern Gulf of St. Lawrence & sGoSL & 74.1 & 38 & $1971-2008$ & 38 & $1971-2008$ & q-corrected biomass \\
Western Scotian Shelf & WSS & 73.3 & 38 & $1970-2007$ & 38 & $1970-2007$ & q-corrected biomass \\
\hline
\end{tabular}

ecosystems in which they are found; both species of herring are important forage fish prey for a myriad of predators, including cod, which are in turn a dominant component of the predatory groundfish guild in each ecosystem.

Sources of population biomass (either surveybased or stock assessment-based estimates) and annual catches are provided by Bundy et al. (2012, this Theme Section). Overall, data time series ranged from 1946 to 2009, although time-ranges for specific ecosystems varied based on available data for each system. Annual biomass and catch of cod or herring from surveys or assessments were standardized to tons per square kilometer of each ecosystem prior to analysis by dividing by ecosystem area. We note that estimates of ecosystem area are not necessarily indicative of habitable area, particularly for herring that are more coastal (e.g. the entire eastern Bering Sea is not inhabited by Pacific herring).

We used an annual surplus production modeling approach to evaluate drivers of stock productivity. This choice was based on the recognition that environmental and trophodynamic effects are most directly manifest in stock productivity because this metric integrates effects on growth, mortality and recruitment. Moreover, the surplus production approach allowed us to conduct comparative analysis across ecosystems using a common framework and currency. The annual surplus production $\left(\mathrm{ASP}_{t}\right)$ of a species in year $t$ was calculated as:

$$
\mathrm{ASP}_{t}=B_{t+1}-B_{t}+C_{t}
$$

where $C_{t}$ is annual catch and $B_{t}$ and $B_{t+1}$ are the mean biomass estimates in years $t$ and $t+1$, respec- tively. In some systems, biomass estimates from surveys contained one or more positive outliers, typically caused by a single survey tow containing unusually high catches. These high catch events most likely reflect differences in catchability or species aggregation rather than true variation in annual production. Preliminary analyses indicated that the inclusion of anomalously large biomass estimates led to unrealistic rates of increase in population biomass from time $t$ to $t+1$ and subsequently produced extraordinarily high, then low, ASP values when estimated survey biomass returned to levels that preceded the outlier. We therefore smoothed biomass time series to account for this observation error by using a Kalman filter (i.e. local level structural time-series model, StructTS() function in $\mathrm{R}_{i} \mathrm{R}$ Development Core Team 2010). This approach implemented an autoregressive integrated moving average (ARIMA[0,1,1]) model and appeared to have little effect in most systems (particularly for biomass estimated from stock assessments) but was able to reduce noise and eliminate anomalous biomass estimates for several ecosystems and species (Fig. 1).

To identify covariates that best predict inter-annual variation in ASP for each species from each ecosystem, we statistically fit multiple models, each containing different combinations of covariates, and used multi-model inference to identify the weight of evidence in support of each covariate (Burnham \& Anderson 2002). In particular, we fit a null model where ASP varied randomly around a mean value (i.e. no relationship to biomass) and a Schaefer surplus production model (Hilborn \& Walters 1992) where ASP exhibited a parabolic relationship with biomass 


\section{Herring}
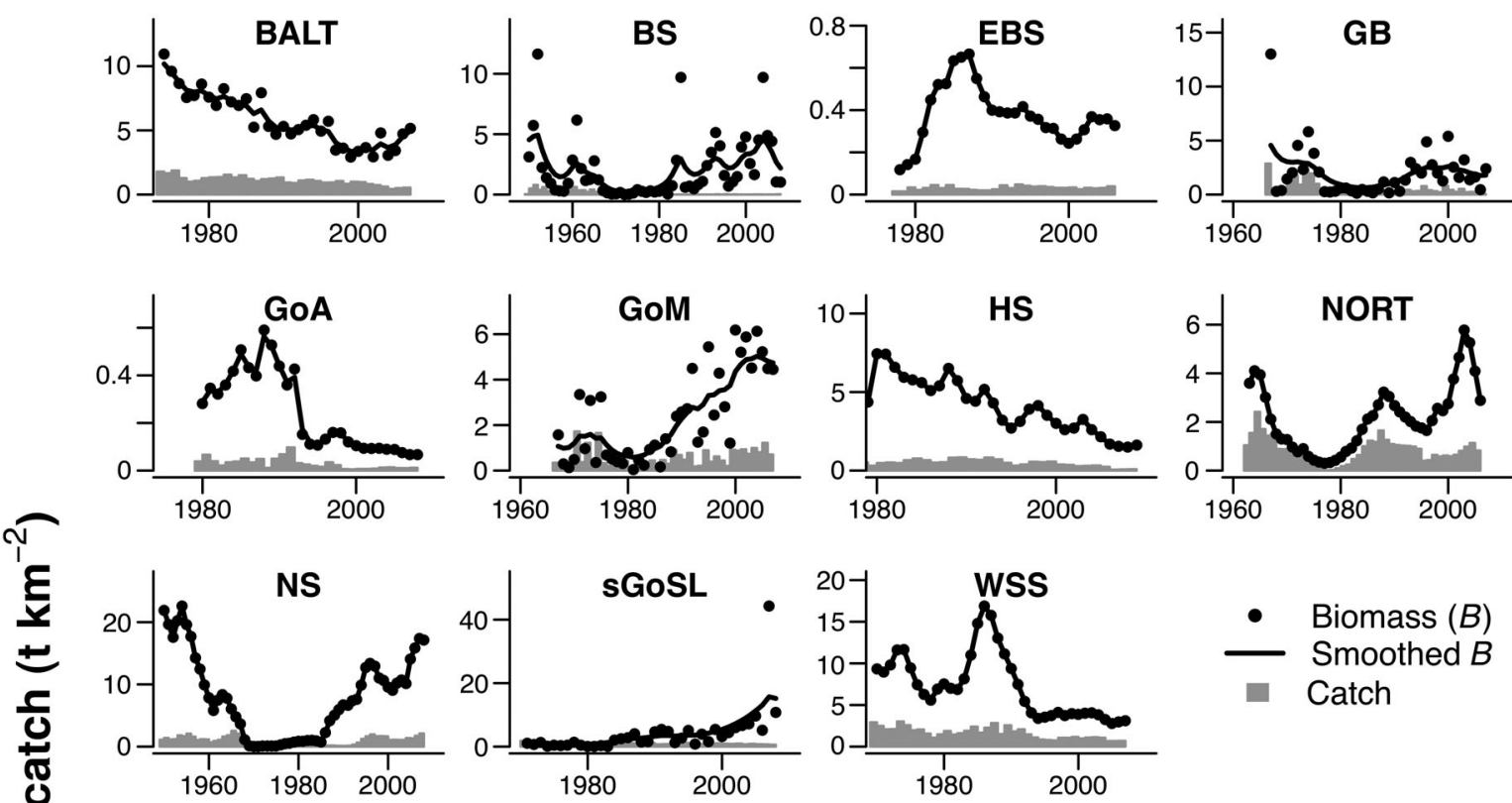

- Biomass $(B)$

- Smoothed $B$

- Catch

क
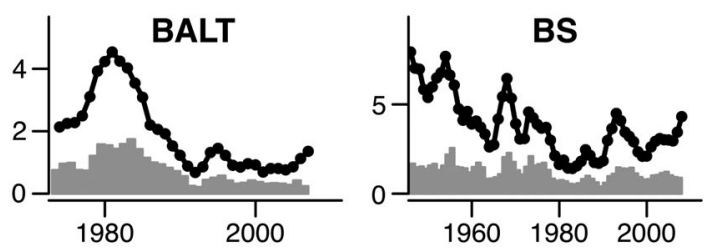

Cod
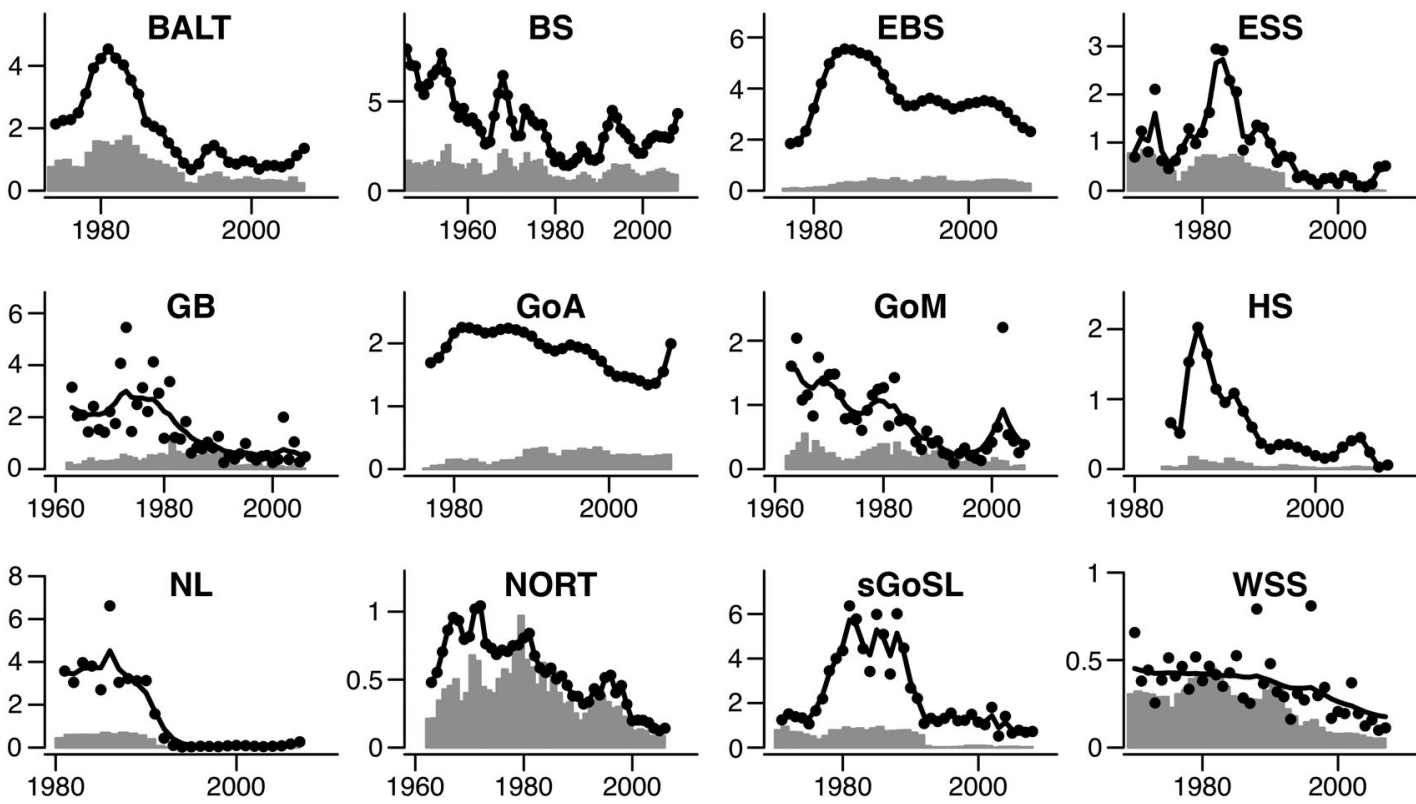

\section{Year}

Fig. 1. Regional time series of observed biomass, Kalman-filtered (smoothed) biomass, and observed harvest (catch) for cod and herring in different ecosystems. See Table 1 for ecosystem abbreviations

according to parameters $r$ (maximum annual perbiomass rate of population increase) and $K$ (equilibrium population biomass in the absence of fishing). To this simple production model we added a number of biological and environmental covariates $(m)$ that modified annual surplus production additively such that:

$$
\mathrm{ASP}_{t}=r B_{t}\left(1-\frac{B_{t}}{K}\right)+\sum_{i=1}^{I I} \gamma_{i} X_{i, t}+\varepsilon_{t}
$$

where $X_{i, t}$ is the $Z$-score standardized value of covariate $i$ in year $t, \gamma_{\mathrm{i}}$ describes the effect of covariate $i$, and $\varepsilon_{\mathrm{t}}$ is an independently and normally distributed random variable with variance $\sigma\left(\sim N\left[0, \sigma^{2}\right]\right)$. 
We selected covariates that indexed important trophodynamic or ecosystem processes and were broadly available for most of the systems in our study (see Fu et al. 2012, this Theme Section). Our selected biophysical covariates included mean sea surface temperature (T) and wind speed (V) as well as 2 atmospheric indices of marine productivity depending on ocean basin: the Pacific Decadal Oscillation (PDO) for Pacific ecosystems and the North Atlantic Oscillation index (NAO) for Atlantic systems. We hypothesized that ASP may vary as a function of prey and/or predator abundance, so we also included herring biomass as prey in the models for cod (lagged by 1 yr to reflect subsequent production), and cod biomass within the same year as an index of predation in herring models. In addition to the aforementioned models with normally distributed errors, we additionally fit both the null (i.e. random variation around the mean) and simple production model (i.e. no covariates) using autocorrelated residuals (i.e. $\varepsilon_{t}=\varphi \cdot \varepsilon_{t-1}$ $+v_{t}$ ) where $\varphi$ represents the degree of temporal autocorrelation and $v_{t}$ is an independently and normally distributed random variable (i.e. $v_{t} \sim \mathrm{N}\left[0, \sigma^{2}\right]$ ).

We fit all models to the data by minimizing the negative $\log$-likelihood using the optim() or $\operatorname{lm}()$ functions of the R statistical system (R Development Core Team 2010; www.r-project.org); a penalized likelihood was used to constrain $K$ (and subsequently $B_{\mathrm{MSY}}$ ) within reasonable bounds (i.e. $0<K<40$ ) for models that failed to converge on biologically realistic parameter estimates (e.g. Collie \& DeLong 1999). We then ranked candidate models using Akaike's information criterion corrected for small sample sizes $\left(\mathrm{AIC}_{\mathrm{c} i}\right.$ Burnham \& Anderson 2002). We expect that most species will exhibit some degree of autocorrelation in errors of surplus production. However, because our objective is to use a comparative approach to evaluate the relative effect of including environmental covariates on emergent biological reference points from surplus production models (rather than find the best fitting model for each system per se), we choose to only include models with independent errors in model averaged parameter estimates. We recognize that for systems where cod or herring exhibit a high degree of autocorrelation, these may not be the top selected models. For all models with independent, normally distributed errors (i.e. not autocorrelated), we used the Akaike weight $\left(W_{i}\right)$ of each model (i) to find a $95 \%$ confidence set of models (i.e. the subset of top-ranked models whose Akaike weights together comprise $95 \%$ of the total). Variable weights $\left(W_{+(j)}\right)$, which measure the explanatory power of each predictor variable $(j)$, were calculated by summing the normalized Akaike weights $\left(W_{i}^{\prime}\right)$ of all models in the $95 \%$ subset in which that variable appeared. We also calculated model averaged estimates $\left(\hat{\bar{\beta}}_{j}\right)$ for each parameter across all models by summing the product of the normalized model Akaike weights and parameter coefficient values $\left(\hat{\beta}_{i, j}\right)$ for each model across all models $(R)$ in the $95 \%$ subset (Burnham \& Anderson 2002) such that:

$$
\hat{\bar{\beta}}_{j}=\sum_{i=1}^{R} W_{i}^{\prime} \hat{\beta}_{i, j} \text { where } W_{i}^{\prime}=\frac{W_{i}}{\sum_{i=1}^{R} W_{i}}
$$

The weighted unconditional variance estimator for the same model averaged parameter is then given by:

$$
\operatorname{var}\left(\hat{\bar{\beta}}_{j}\right)=\left[\sum_{i=1}^{R} W_{i}^{\prime} \sqrt{\operatorname{var}\left(\hat{\beta}_{i, j} \mid g_{i}\right)+\left(\hat{\beta}_{i, j}-\hat{\bar{\beta}}_{j}\right)^{2}}\right]^{2}
$$

where $\hat{\bar{\beta}}_{j}$ is the averaged parameter estimate from Eq. (3) and $\operatorname{var}\left(\hat{\bar{\beta}}_{i, j} \mid g_{i}\right)$ is the variance in $\hat{\bar{\beta}}_{j}$ conditional on model $g_{i}$. We similarly calculated the model-averaged mean response and unconditional variance of the response variable by replacing $\beta$ in Eqs. (3) \& (4) with estimated surplus production $\left(\mathrm{ASP}_{i}\right)$ from each model in the $95 \%$ subset. The unconditional variance was used to construct $95 \%$ confidence intervals around the model-averaged mean response assuming that the variable was normally distributed. Lastly, we calculated MSY and $B_{\mathrm{MSY}}$ reference points for ecosystem- and species-specific models using model averaged parameter values for $r$ and $K$ as:

$$
\begin{aligned}
\mathrm{MSY} & =\frac{r \cdot K}{4} \\
B_{\mathrm{MSY}} & =\frac{K}{2}
\end{aligned}
$$

\section{RESULTS}

Biomass and catch time series displayed considerable variability within and across ecosystems for each species (Fig. 1). In general, herring biomass was higher and more variable than cod biomass; across ecosystems, coefficients of variation (i.e. standard deviation/mean; CV) for herring biomass before Kalman filtering averaged $80.9 \%$ whereas cod CVs were $63.5 \%$. Similarly, overall regional mean herring biomass across years ranged from 0.02 to $22.58 \mathrm{t}$ $\mathrm{km}^{-2}$, while average cod biomass ranged from 0.03 to $7.94 \mathrm{t} \mathrm{km}^{-2}$. In 5 of the 13 ecosystems we examined (BALT, EBS, GoA, HS, and WSS; see Table 1 for abbreviations), herring and cod exhibited similar temporal trends in biomass (mean Pearson's correlation coefficient of 0.76 ), whereas in the remaining eco- 
systems, patterns of cod and herring biomass were decoupled, or in the case of GoM and NORT, negatively correlated (correlation coefficients of -0.52 and -0.70, respectively; Fig. 1).

ASP dynamics within ecosystems were also more variable for herring than cod (mean $\mathrm{CV}$ values of 5.6 and 2.8, respectively), and exhibited a wider range of average levels across ecosystems (ranges of
-1.47 to 5.69 and -0.56 to $2.56 \mathrm{t} \mathrm{km}^{-2}$, for herring and cod, respectively; Fig. 2). Pacific cod exhibited lower mean surplus production rates $\left(0.2 \pm 0.1 \mathrm{t} \mathrm{km}^{-2}\right)$ than Atlantic cod in the ecosystems we examined $\left(0.44 \pm 0.11 \mathrm{t} \mathrm{km}^{-2}\right)$, but there were no clear differences in ASP for herring from Atlantic or Pacific ecosystems $\left(0.79 \pm 0.15\right.$ and $0.37 \pm 0.34 \mathrm{t} \mathrm{km}^{-2}$, respectively).

\section{Herring}
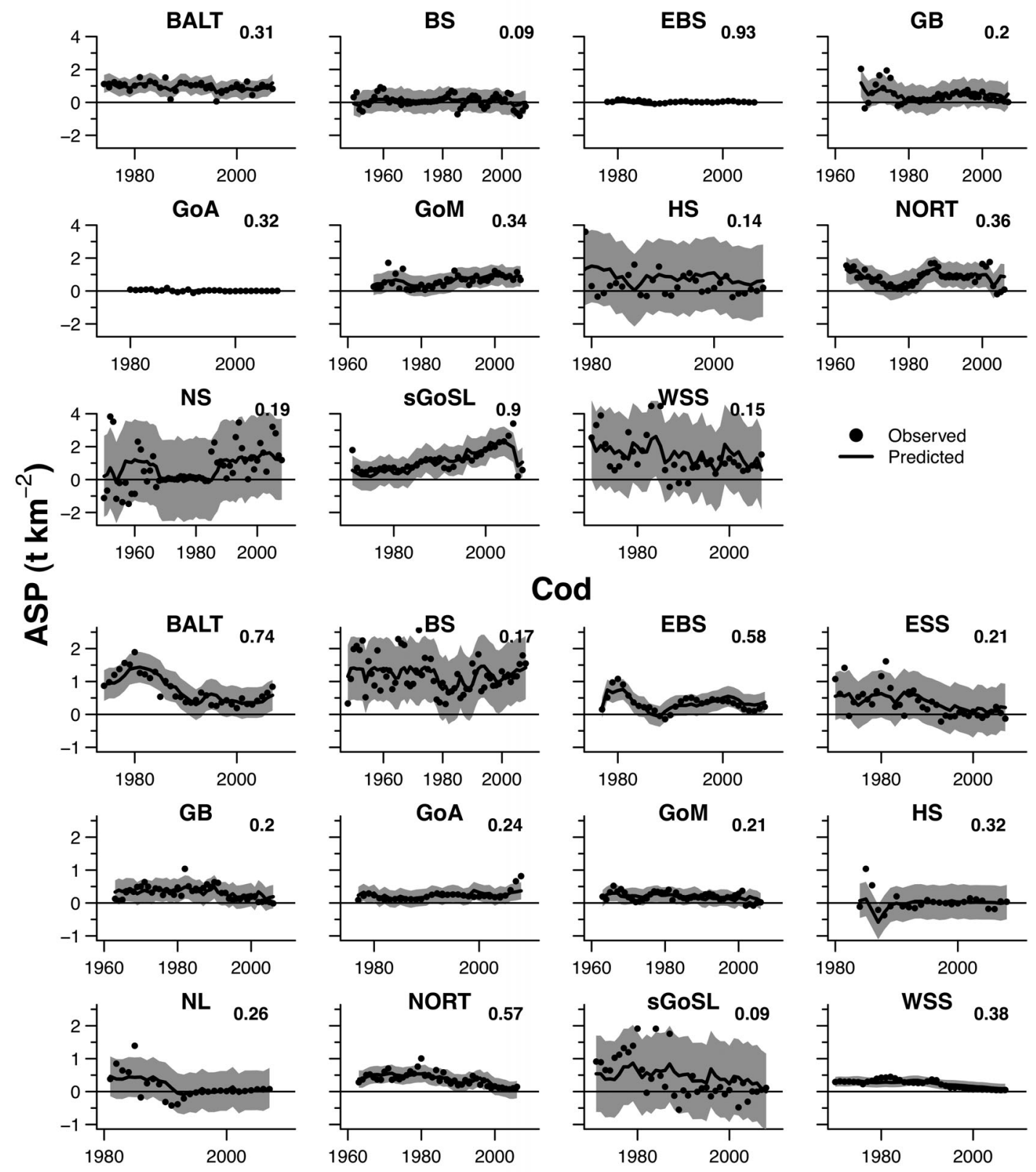

- Observed Predicted
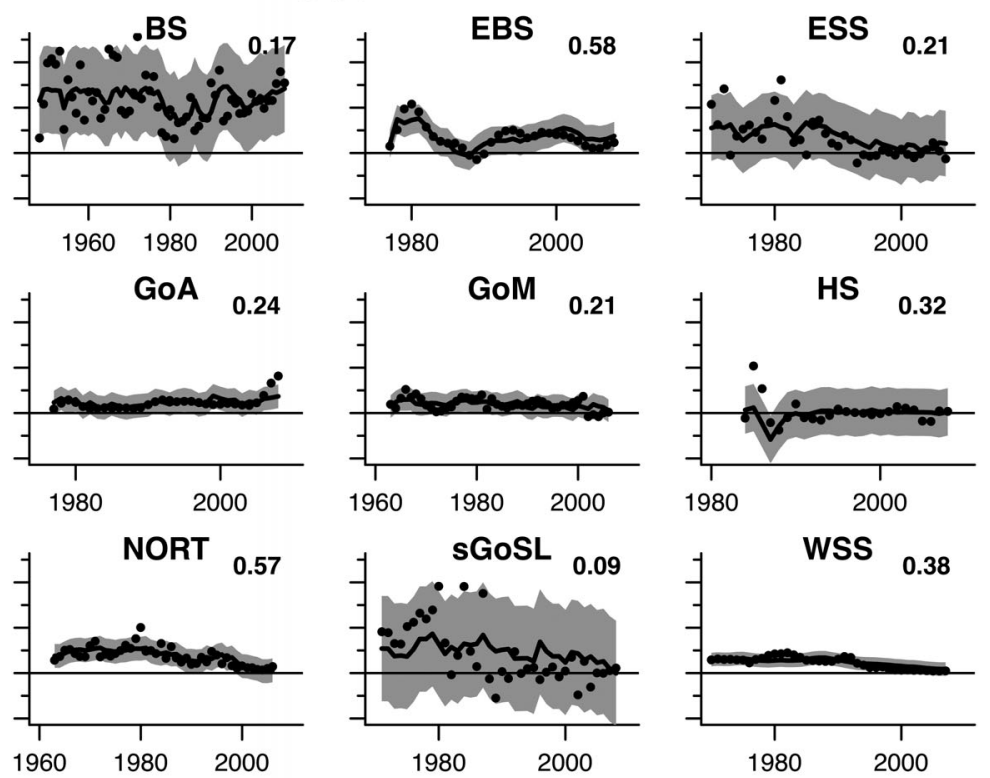

Year

Fig. 2. Observed annual surplus production values (ASP; points) for herring and cod from each ecosystem. Solid lines: model averaged predicted values from top $\mathrm{AIC}_{\mathrm{c}}$ selected models. Shading: $95 \%$ confidence intervals; numerical values: $\mathrm{R}^{2}$ values for model fits. See Table 1 for ecosystem abbreviations 
We were able to achieve credible fits to Schaefer production models for 12 of the 13 ecosystems for herring, and 9 of 13 ecosystems for cod; GB herring, and NL and WSS cod production dynamics were not well described by the Schaefer production model (Fig. 3). Furthermore, parameter estimates for EBS cod surplus production should be considered cautiously as the estimate for $K$ was near the upper limit set by the penalized likelihood (i.e. 40). Lastly, although the estimate of $K$ for cod from BALT was substantially below the upper limit, it is still well outside the range of the data and should also be considered cautiously.

\section{Herring}
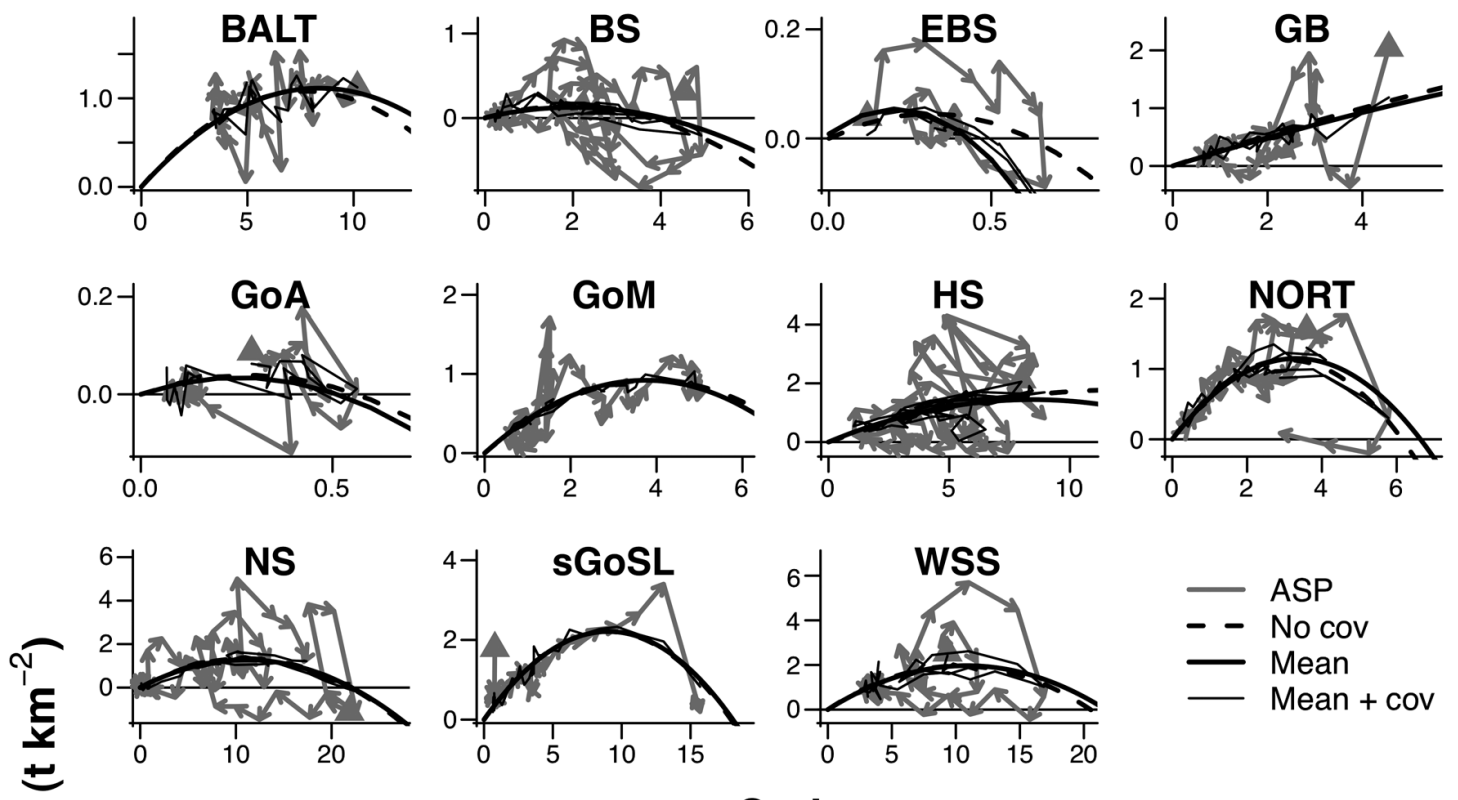

$\frac{0}{4}$
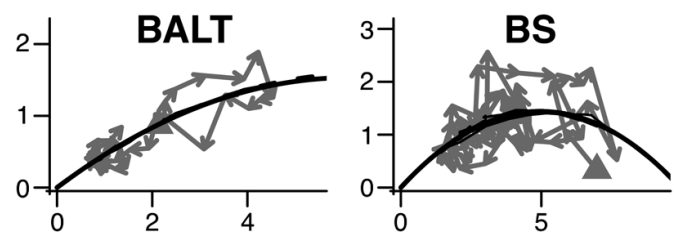

Cod
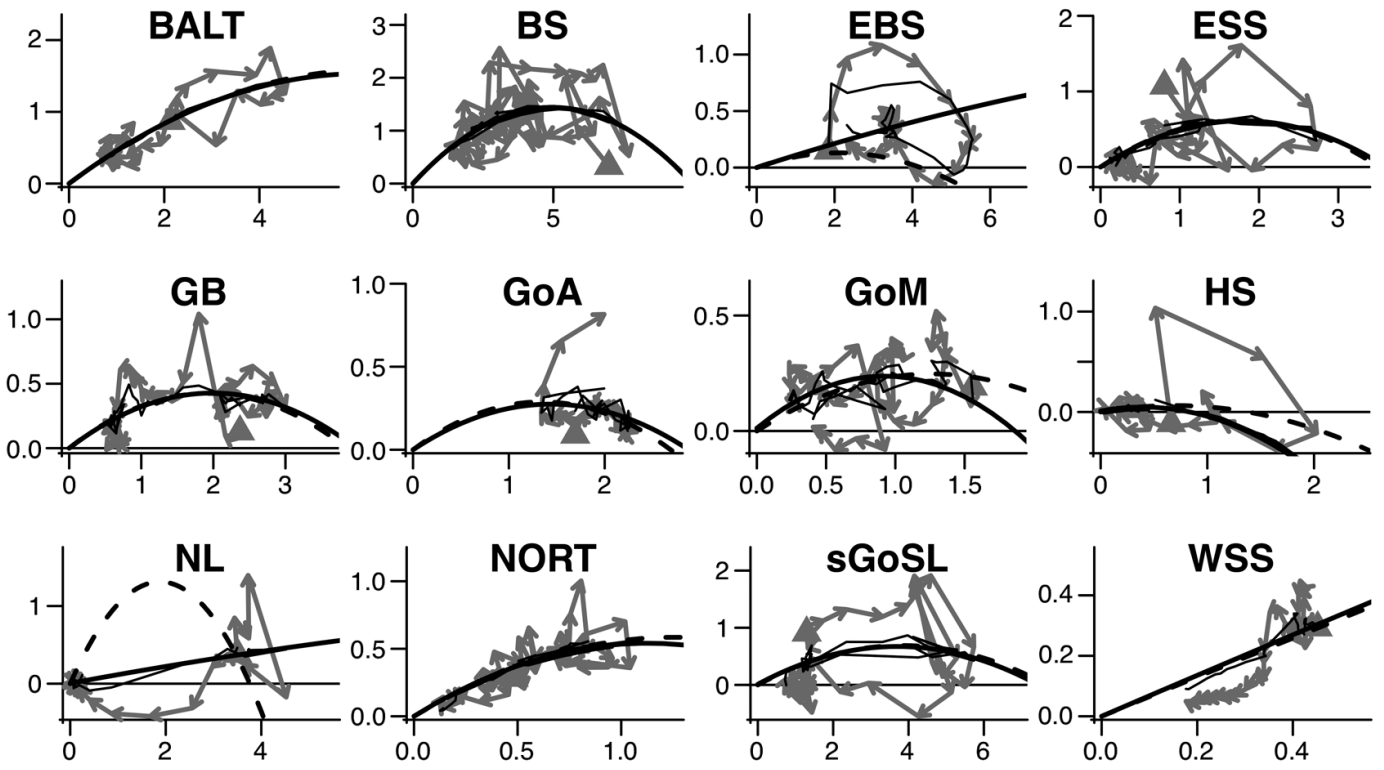

Biomass $\left(\mathrm{t} \mathrm{km}^{-2}\right)$

Fig. 3. Observed annual surplus production (ASP) and biomass $\left(\mathrm{t} \mathrm{km}^{-2}\right)$ of herring and cod species from each ecosystem (gray arrows; 'ASP'); $\Delta$ : first year in each time series. Predicted ASP values from averaged parameter estimates of top AICc selected models (thin black lines; 'Mean + cov'), estimates of ASP curves from models without covariates (dashed 'No cov.'), and ASP curves from covariate models under mean environmental conditions (thick black lines; 'Mean') are also shown. See Table 1 for 
Although, temporal autocorrelation in surplus production was strong for both species from most ecosystems $(\varphi>0.2$; Table 2$)$, ecological covariates appeared to explain a large portion of the observed autocorrelation; in approximately $40 \%$ of the ecosystems we analyzed, $\mathrm{AIC}_{\mathrm{C}}$ selected one or more models with ecological covariates above the simple Schaefer model with autocorrelation (Table 3). That said, we did not find overwhelming support for one specific model with covariates; for most ecosystems there were multiple models that equally explained surplus production for cod or herring species (Table 3). Model-averaged parameter weights and coefficient values indicated that temperature was an important predictor of ASP dynamics, especially for herring (i.e. values were often non-zero; Tables $2 \& 4$ ), but the direction of the effect was species- and systemdependent (Fig. 4). For herring, positive anomalies in sea surface temperature were positively correlated with surplus production in WSS, NS, GoM and HS ecosystems, whereas herring production was significantly reduced during warm conditions in NORT and BS (Fig. 4). For cod, positive anomalies in annual seasurface temperatures were associated with marginal declines in ASP in most ecosystems; this was most notable in GoA and GoM (Fig. 4). Average parameter weights and coefficient values for terms representing variability in wind and atmospheric indices indicated that both were important predictors of ASP dynamics (i.e. values were often non-zero; Table 4 \& Fig. 4 , respectively), yet these factors had mixed effects on herring and cod production, and confidence intervals of mean parameter estimates frequently overlapped zero (Table 2).

We found some evidence of bottom-up or facilitative processes between herring and cod. In roughly a third of the ecosystems we examined, mean parameter weights for the effect of herring (lagged by 1 yr)

Table 2. Model-averaged parameter values for (A) herring and (B) cod from each ecosystem (excluding models with autocorrelation). Note that values have not been standardized to mean biomass for each species from each ecosystem. Parentheses: unconditional standard error for each average parameter value. Bold: significant parameter values (i.e. estimate interval does not overlap zero). Italics: ecosystems where surplus models converged on the upper limit for $K(40)$ and that should be considered cautiously. B: biomass; MSY: maximum sustainable yield; T: sea surface temperature; PDO/NAO: Pacific Decadal Oscillation or North Atlantic Oscillation index, given as applicable; cod: biomass of $\operatorname{cod}_{i}$ herring $_{t-1}$ : biomass of herring in the previous year; $\varphi$ : degree of temporal autocorrelation; $r$ : maximum annual per-biomass rate of population increase; $K$ : equilibrium population biomass in the absence of fishing; NA: data not available. See Table 1 for ecosystem abbreviations

\begin{tabular}{|c|c|c|c|c|c|c|c|c|c|}
\hline $\begin{array}{l}\text { (A) Herring } \\
\text { Ecosystem }\end{array}$ & $B_{\mathrm{MSY}}$ & MSY & $\mathrm{T}$ & Wind speed & $\mathrm{PDO} / \mathrm{NAO}$ & Cod & $\varphi$ & $r$ & $K$ \\
\hline BALT & 8.39 (3.59) & $1.11(0.07)$ & $0.11(0.06)$ & NA & $0.09(0.05)$ & $0.04(0.04)$ & $0.04(0.08)$ & $0.26(0.04)$ & $16.78(7.18)$ \\
\hline BS & 2.01 (1.76) & $0.12(0.06)$ & $-0.08(0.04)$ & $-0.02(0.02)$ & $0.02(0.02)$ & $-0.02(0.02)$ & $0.41(0.08)$ & $0.12(0.07)$ & 4.02 (3.52) \\
\hline EBS & $0.21(0.23)$ & $0.05(0.03)$ & 0 & 0 & 0 & $0.03(0.02)$ & $0.29(0.08)$ & $0.48(0.26)$ & $0.42(0.46)$ \\
\hline$G B$ & $20.0(1.00)$ & $2.56(1.14)$ & $-0.04(0.04)$ & $0(0.01)$ & $0.11(0.06)$ & $0.04(0.04)$ & $0.20(0.08)$ & $0.26(2.28)$ & $40.0(2.00)$ \\
\hline GoA & $0.26(0.21)$ & $0.03(0.01)$ & 0 & $-0.02(0.01)$ & 0 & $0.03(0.01)$ & $0.08(0.11)$ & $0.23(0.10)$ & $0.52(0.42)$ \\
\hline GoM & $3.75(2.04)$ & $0.92(0.07)$ & $0.05(0.04)$ & $0(0.01)$ & $0.01(0.02)$ & $0.03(0.03)$ & $0.09(0.07)$ & $0.49(0.07)$ & $7.5(4.08)$ \\
\hline HS & 8.44 (3.35) & $1.44(0.19)$ & $0.04(0.05)$ & $0.05(0.06)$ & $-0.19(0.13)$ & $-0.24(0.14)$ & $0.28(0.07)$ & $0.34(0.11)$ & $16.88(6.70)$ \\
\hline NORT & $3.32(1.87)$ & $1.15(0.07)$ & $-0.12(0.06)$ & NA & $0(0.02)$ & $0.02(0.03)$ & $0.44(0.08)$ & $0.69(0.07)$ & $6.64(3.74)$ \\
\hline NS & $11.05(8.28)$ & $1.28(0.23)$ & $0.16(0.12)$ & $-0.06(0.07)$ & $0.05(0.06)$ & NA & $0.25(0.07)$ & $0.23(0.06)$ & $22.1(16.56)$ \\
\hline sGoSL & 9.04 (5.89) & $2.21(0.11)$ & $0.01(0.02)$ & $0.04(0.04)$ & $-0.17(0.07)$ & $0.01(0.02)$ & $0.31(0.08)$ & $0.49(0.04)$ & $18.08(11.78)$ \\
\hline WSS & $10.86(5.84)$ & $1.97(0.22)$ & $0.41(0.20)$ & $0.15(0.12)$ & $-0.04(0.06)$ & $0.18(0.15)$ & $0.43(0.09)$ & $0.36(0.08)$ & $21.72(11.68)$ \\
\hline \multicolumn{10}{|l|}{ (B) Cod } \\
\hline Ecosystem & $B_{\mathrm{MSY}}$ & MSY & $\mathrm{T}$ & Wind speed & $\mathrm{PDO} / \mathrm{NAO}$ & Herring $_{t-1}$ & $\varphi$ & $r$ & $K$ \\
\hline BALT & $6.15(1.74)$ & $1.53(0.09)$ & $0(0.01)$ & NA & $-0.01(0.02)$ & $0.02(0.02)$ & $0.41(0.07)$ & $0.5(0.1)$ & $12.3(3.48)$ \\
\hline BS & $4.97(2.60)$ & $1.44(0.07)$ & $0.02(0.02)$ & $0.03(0.03)$ & $0(0.01)$ & $0.03(0.03)$ & $0.15(0.06)$ & $0.58(0.05)$ & $9.94(5.20)$ \\
\hline$E B S$ & $20.0(1.00)$ & $1.12(1.08)$ & $-0.01(0.01)$ & $0(0.01)$ & $0.01(0.01)$ & $-0.29(0.03)$ & $0.87(0.23)$ & $0.11(2.16)$ & $40.0(2.00)$ \\
\hline ESS & $1.8(0.98)$ & $0.61(0.07)$ & $-0.03(0.03)$ & $0.02(0.03)$ & $-0.03(0.03)$ & NA & $0.24(0.07)$ & $0.68(0.14)$ & $3.60(1.96)$ \\
\hline GB & $1.99(1.19)$ & $0.43(0.04)$ & $0(0.01)$ & $-0.05(0.02)$ & $0.04(0.02)$ & $-0.01(0.01)$ & $0.26(0.07)$ & $0.43(0.07)$ & $3.98(2.38)$ \\
\hline GoA & $1.44(1.00)$ & $0.27(0.06)$ & $-0.05(0.02)$ & $-0.01(0.01)$ & $-0.01(0.01)$ & $-0.02(0.02)$ & $0.99(0.60)$ & $0.38(0.12)$ & $2.88(2.00)$ \\
\hline GoM & $0.92(0.59)$ & $0.23(0.04)$ & $-0.05(0.02)$ & 0 & $0(0.01)$ & $-0.01(0.01)$ & $0.28(0.07)$ & $0.50(0.14)$ & $1.84(1.18)$ \\
\hline HS & $0.39(0.64)$ & $0.04(0.06)$ & $-0.02(0.02)$ & $0(0.01)$ & $0.01(0.01)$ & $0.03(0.03)$ & $0.21(0.13)$ & $0.21(0.19)$ & $0.78(1.28)$ \\
\hline$N L$ & $19.2(3.29)$ & $1.10(2.28)$ & $0.01(0.01)$ & $0.06(0.04)$ & $-0.02(0.02)$ & $N A$ & $0.21(0.09)$ & $0.11(1.39)$ & $38.4(6.58)$ \\
\hline NORT & $1.13(0.39)$ & $0.54(0.03)$ & $-0.02(0.02)$ & NA & $0(0.01)$ & $-0.02(0.02)$ & $0.31(0.07)$ & $0.96(0.15)$ & $2.26(0.78)$ \\
\hline sGoSL & 3.71 (2.29) & $0.66(0.14)$ & $-0.03(0.04)$ & $0.02(0.03)$ & $-0.1(0.07)$ & $-0.02(0.03)$ & $0.23(0.09)$ & $0.36(0.12)$ & $7.42(4.58)$ \\
\hline$W S S$ & $19.86(1.46)$ & $6.76(1.47)$ & 0 & 0 & 0 & $0.03(0.01)$ & $0.71(0.1)$ & $0.68(2.01)$ & $39.72(2.92)$ \\
\hline
\end{tabular}




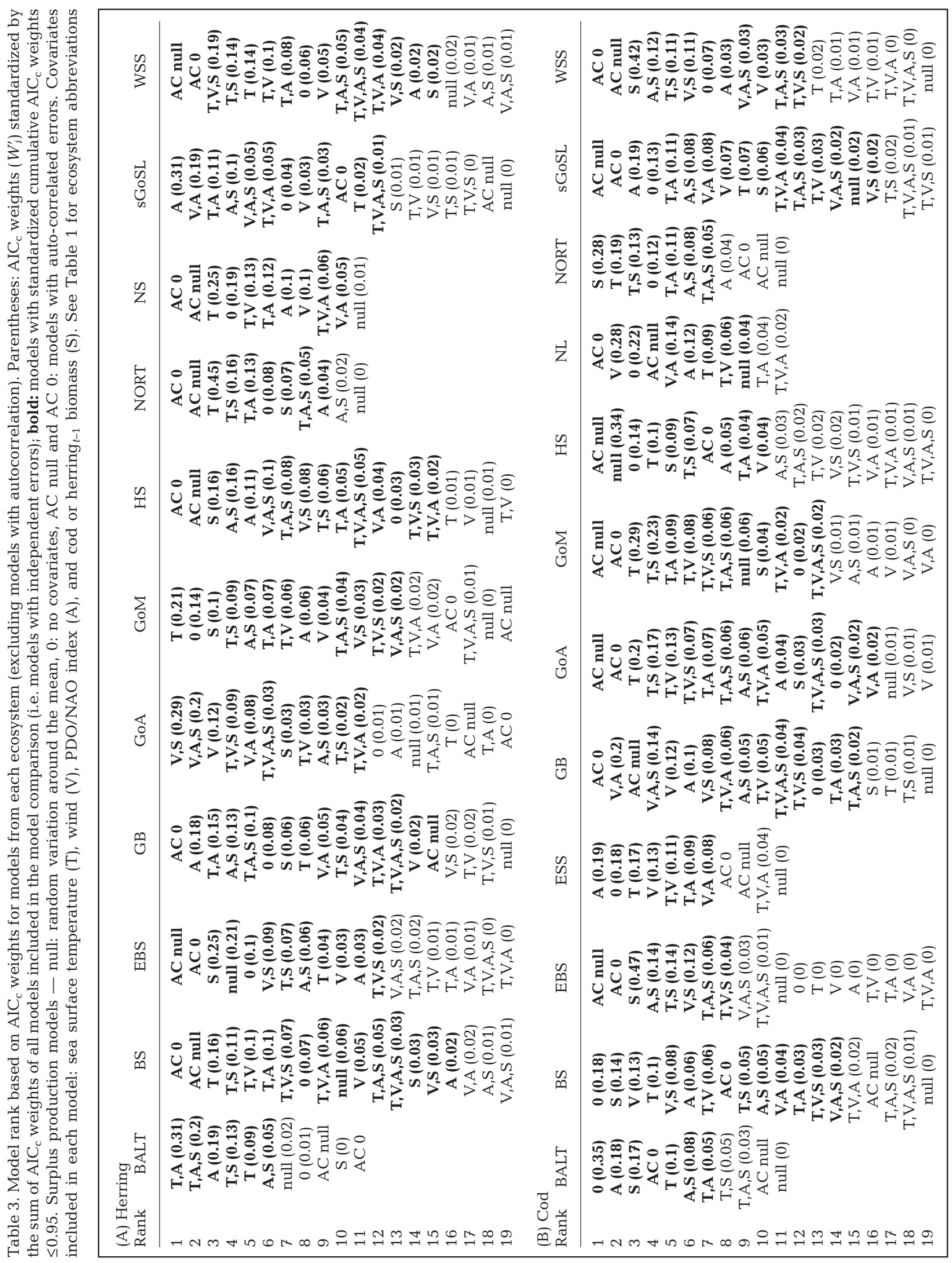


Table 4. Average surplus production parameter $\mathrm{AIC}_{\mathrm{c}}$ weights for (A) herring and (B) cod. Bold: overall regional means. Italics: ecosystems where surplus models converged on the upper limit for $K(40)$ and should be considered cautiously. Wind = wind speed. See Table 1 for ecosystem abbreviations and Table 2 for column heading abbreviations

\begin{tabular}{|c|c|c|c|c|c|c|}
\hline $\begin{array}{l}\text { (A) Herring } \\
\text { Ecosystem }\end{array}$ & ${ }^{g} r$ & $K$ & $\mathrm{~T}$ & Wind & $\mathrm{PDO} / \mathrm{NAO}$ & Cod \\
\hline BALT & 1.00 & 1.00 & 0.76 & 0.00 & 0.77 & 0.39 \\
\hline BS & 0.93 & 0.93 & 0.72 & 0.37 & 0.28 & 0.34 \\
\hline EBS & 0.78 & 0.78 & 0.16 & 0.18 & 0.14 & 0.56 \\
\hline$G B$ & 1.00 & 1.00 & 0.41 & 0.17 & 0.76 & 0.41 \\
\hline GoA & 1.00 & 1.00 & 0.21 & 0.91 & 0.38 & 0.73 \\
\hline GoM & 1.00 & 1.00 & 0.51 & 0.18 & 0.27 & 0.39 \\
\hline HS & 1.00 & 1.00 & 0.29 & 0.32 & 0.63 & 0.73 \\
\hline NORT & 1.00 & 1.00 & 0.80 & 0.00 & 0.22 & 0.29 \\
\hline NS & 1.00 & 1.00 & 0.56 & 0.34 & 0.33 & 0.00 \\
\hline sGoSL & 1.00 & 1.00 & 0.24 & 0.36 & 0.90 & 0.20 \\
\hline WSS & 1.00 & 1.00 & 0.81 & 0.46 & 0.24 & 0.48 \\
\hline Mean & 0.97 & 0.97 & 0.5 & 0.3 & 0.45 & 0.41 \\
\hline $\begin{array}{l}\text { (B) Cod } \\
\text { Ecosystem }\end{array}$ & $r$ & $K$ & $\mathrm{~T}$ & Wind & PDO/NAO & Herring $_{t-1}$ \\
\hline BALT & 1.00 & 1.00 & 0.19 & 0.00 & 0.32 & 0.31 \\
\hline BS & 1.00 & 1.00 & 0.28 & 0.37 & 0.21 & 0.38 \\
\hline$E B S$ & 1.00 & 1.00 & 0.25 & 0.16 & 0.19 & 1.00 \\
\hline ESS & 1.00 & 1.00 & 0.38 & 0.34 & 0.39 & 0.00 \\
\hline GB & 1.00 & 1.00 & 0.24 & 0.77 & 0.66 & 0.38 \\
\hline GoA & 1.00 & 1.00 & 0.80 & 0.32 & 0.35 & 0.46 \\
\hline GoM & 0.94 & 0.94 & 0.88 & 0.19 & 0.19 & 0.42 \\
\hline HS & 0.65 & 0.65 & 0.26 & 0.08 & 0.14 & 0.24 \\
\hline$N L$ & 0.96 & 0.96 & 0.19 & 0.49 & 0.29 & 0.00 \\
\hline NORT & 1.00 & 1.00 & 0.50 & 0.00 & 0.25 & 0.55 \\
\hline sGoSL & 0.98 & 0.98 & 0.29 & 0.27 & 0.58 & 0.23 \\
\hline WSS & 1.00 & 1.00 & 0.19 & 0.19 & 0.21 & 0.85 \\
\hline Mean & 0.96 & 0.96 & 0.37 & 0.26 & 0.32 & 0.4 \\
\hline
\end{tabular}

on cod, or cod on herring (in the same year), were greater than 0.5, indicating models with terms for trophodynamic covariates comprised more than $50 \%$ of the cumulative $\mathrm{AIC}_{\mathrm{c}}$ model weights from each ecosystem (Table 4). In BALT, BS, and HS, increased biomass of herring was associated with slight increases in cod ASP the following year, whereas in EBS, GB, GoM, and sGoSL, and NORT, cod ASP was negatively correlated with herring biomass in the previous year (Fig. 4). However, in most ecosystems, parameter estimates indicate a weak effect of herring biomass in a previous year on cod ASP, since model averaged parameter intervals often overlapped zero (except for EBS and WSS, which should be considered cautiously; Table 2). In contrast, cod biomass was an important predictor of herring surplus production in the same year, especially in EBS, GoA, HS and WSS (Table 2), but somewhat unexpectedly was positivity correlated with ASP in most systems except HS and BS (Fig. 4).
Across ecosystems, there were associations between mean MSY corrected for biomass and biophysical attributes. Mean estimated MSY values for herring were largest in the warmest systems in our study, but colder systems on average exhibited slightly higher estimates of MSY for cod (Fig. 5a). Mean MSY estimates for both species were negatively correlated with mean wind speed across systems, although the pattern was considerably stronger for herring than for cod (Fig. 5b). Finally, mean MSY estimates were differently correlated with the average biomass of predator or prey species; estimated herring MSY values were lower in systems with high mean cod biomass, whereas estimated cod MSY values were higher in systems with higher mean herring biomass (Fig. 5c,d).

Model-averaged estimates of biological reference points varied across ecosystems and species. MSY for both species were always less than $2.5 \mathrm{t} \mathrm{km}^{-2}$, with estimates generally higher for herring than for cod (mean of 0.9 and $0.4 \mathrm{t} \mathrm{km}^{-2}$, respectively). MSY for herring from EBS, BS, and GoA had low values of MSY (0.03 to $0.07 \mathrm{t} \mathrm{km}^{-2}$ ) as compared to the remaining ecosystems where MSY estimates were an order of magnitude larger (0.92 to $2.2 \mathrm{t} \mathrm{km}^{-2}$ ), although differences were much smaller when values were standardized by mean ecosystem biomass. MSY and $B_{\mathrm{MSY}}$ of cod ranged between 0.2 and $1.5 \mathrm{t} \mathrm{km}^{-2}$ and 0.5 and $6.2 \mathrm{t} \mathrm{km}^{-2}$, respectively, and were highest for BALT and lowest for HS (Fig. 6). Similarly, $B_{\mathrm{MSY}}$ was lowest for EBS, BS, and GoA (1.4 to $2.2 \mathrm{t} \mathrm{km}^{-2}$ ) and highest for sGoSL, and generally ranged between 3.3 and $10.9 \mathrm{t} \mathrm{km}^{-2}$. Maximum population growth rate $(r)$ ranged between 0.12 and 0.96 and was relatively constant across ecosystems and species (mean = $0.44 \pm 0.05$; Fig. 6)

Estimated MSY was robust to changes in model formulation; including physical or trophic covariates in surplus production models either had little effect on MSY or resulted in lower estimates of MSY than those of models without covariates (Fig. 6). This may be due to the mitigating effects of $r$, which were more sensitive to inclusion of covariates and exhibited regional and species-specific estimates of $r$ (i.e. both positive and negative deviations from no-covariate models; Fig 6). Lastly, surplus production models with biophysical or trophic covariates had different effects on estimated $B_{\mathrm{MSY}}$. Inclusion of physical covariates sometimes resulted in less conservative, slightly higher estimates of $B_{\mathrm{MSY}}$ than models without covariates. In contrast, surplus production models containing trophic covariates generally resulted in lower or unchanged estimates of $B_{\mathrm{MSY}}$ values as compared to models without covariates (Fig. 6). 

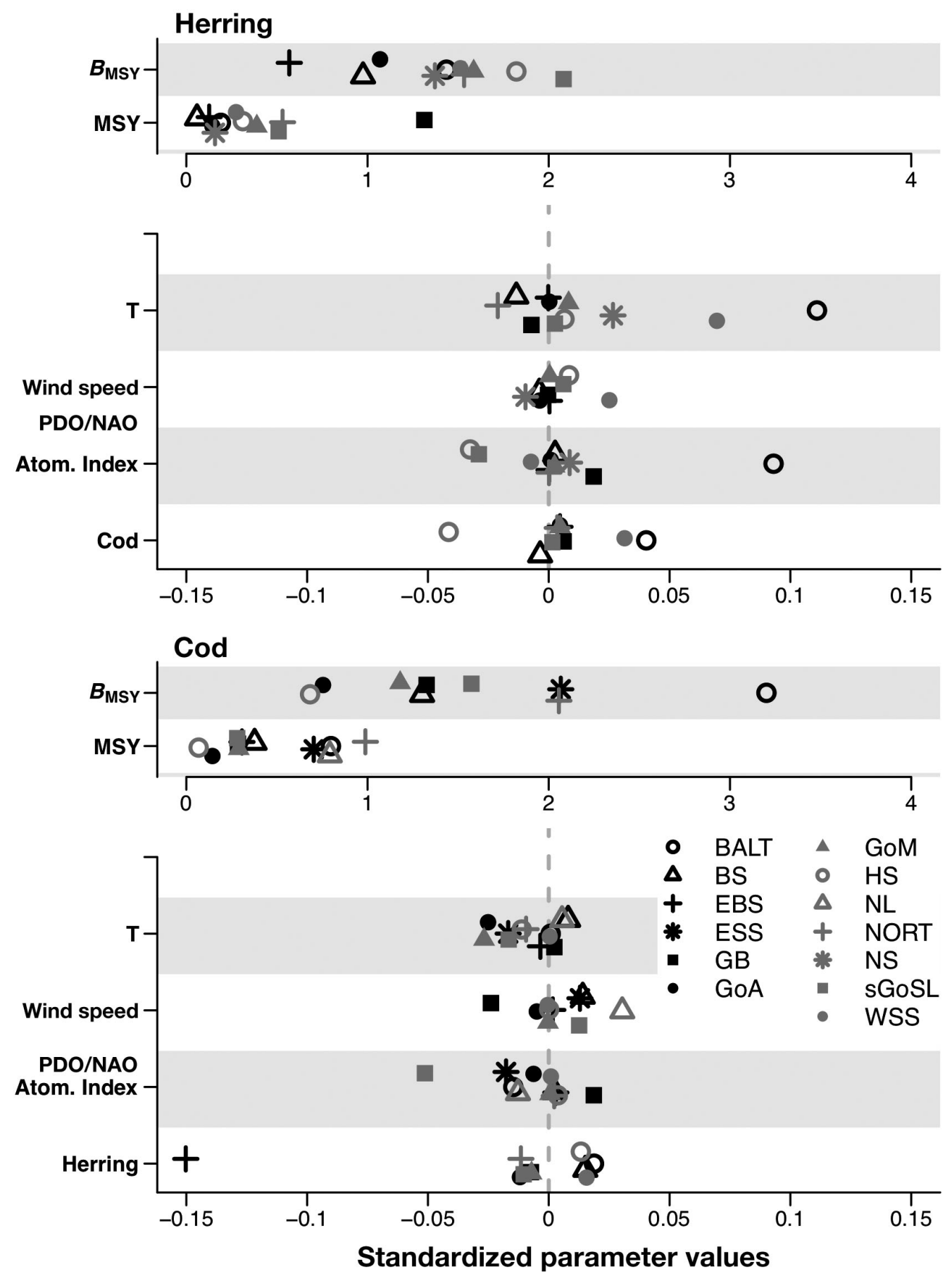

Fig. 4. Ecosystem-specific mean parameter estimates from top $\mathrm{AIC}_{\mathrm{C}}$ selected models for herring and cod. Data are staggered for visual purposes and standardized to mean biomass for each species from each ecosystem. See Tables 1 \& 2 for abbreviations

\section{DISCUSSION}

We conducted a cross-ecosystem comparative analyses to (1) identify whether inter-annual production dynamics are consistently predicted by particular biophysical variables, (2) relate mean production levels to ecosystem attributes, and (3) derive and compare biological reference points. We suggest 2 findings of our analyses are of note. First, biophysical and trophodynamic models commonly improved model fits: production models with biophysical and trophodynamic covariates were often preferred over simple models in most ecosystems. Especially for herring, inclusion of covariates partially accounted for 


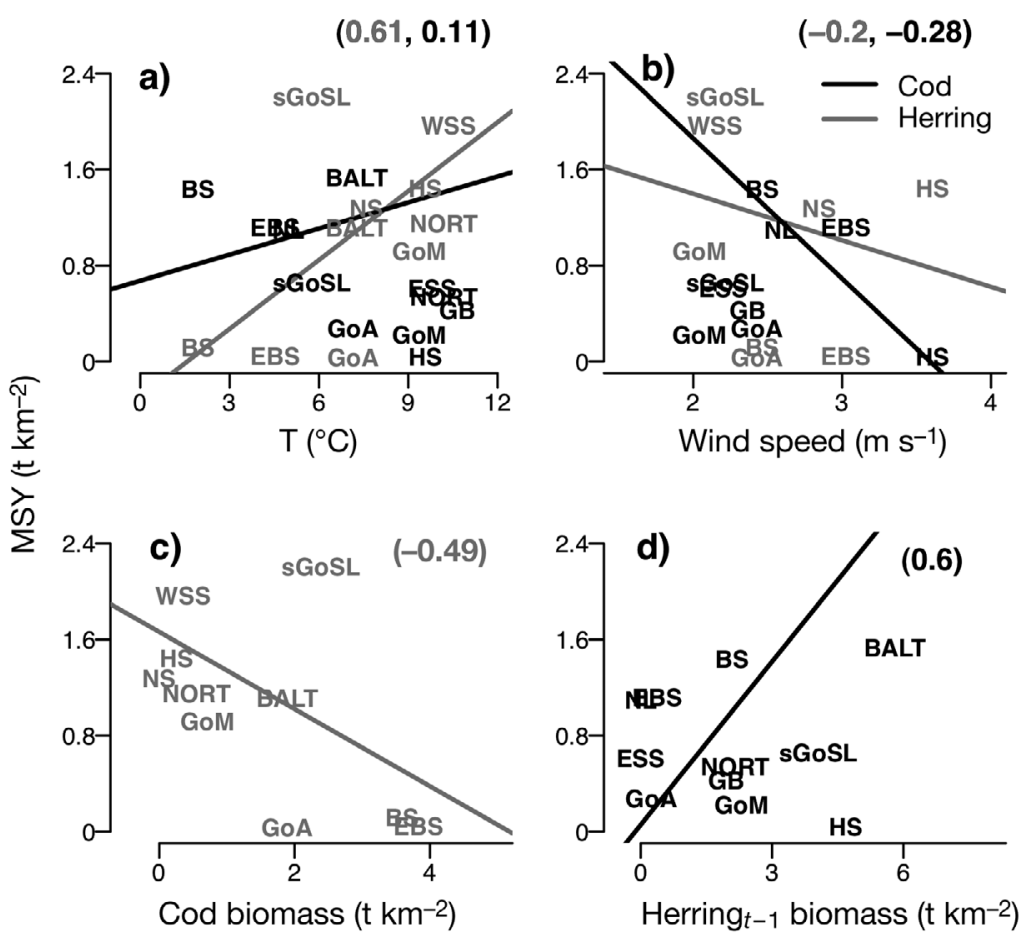

Fig. 5. Maximum sustainable yield (MSY) of cod (black) or herring (gray) species from each ecosystem as a function of mean environmental and biological parameters: (a) sea-surface temperature (T), (b) wind speed, (c) herring predator (cod biomass), and (d) cod prey (herring biomass). Values in brackets: adjusted $\mathrm{R}^{2}$ values of the lines (grey: herring, black: cod). See Table 1 for ecosystem abbreviations

annual variation in auto-correlated errors that typified ASP. Yet, despite considerable inter-annual variability in ASP, no biophysical variables were consistently important in predicting production dynamics across ecosystems. Often individual parameters had different and even opposite effects on predicted ASP for either species from various ecosystems.

Second, inclusion of covariates into production models had species- and ecosystem-specific effects on resultant biological reference points (i.e. MSY and $B_{\mathrm{MSY}}$ ) that reflect regional influences of biophysical or trophodynamic processes on species production. Although $B_{\mathrm{MSY}}$ and $r$ estimates varied between models with and without covariates, estimates of MSY remained relatively unchanged. This is similar to previous studies that found MSY to be robust to changes in bottom-up drivers while biological reference points including MSY were lower if predation was accounted for in production models (i.e. Collie \& Gislason 2001, Tyrrell et al. 2011). In contrast, inclusion of covariates did not universally result in more conservative estimates of $r$ or $B_{\mathrm{MSY}}$, nor did they always differ from parameters estimated from models without biophysical covariates. That said, when differences were observed in models for either species, trophic covariates generally lowered $B_{\mathrm{MSY}}$, whereas physical covariates slightly raised $B_{\mathrm{MSY}}$ from the baseline estimated from models with no covariates. Differences in biological reference point estimates generally were larger when surplus production rates were highly correlated with biophysical covariates. Thus, inclusion of covariates should influence estimates of MSY and $B_{\mathrm{MSY}}$ accordingly for species in regions where production is highly responsive and tightly coupled to measured ecosystem processes.

Surplus production models are simple, computationally efficient methods to derive key population dynamic parameters from time series of population biomass indices (Schnute \& Richards 2002). Our surplus production model fits were greatly improved by application of a Kalman filter to the input data prior to production modeling to smooth out observation error in relative abundance. Although not a common practice in many stock assessments, our analyses suggest that prior data smoothing can stabilize resultant estimates. Similarly, Walters \& Hilborn (2005) used a simple smoother of relative abundance to stabilize estimates of recruitment and also recommend their use in assessment more generally. However, such filtering is not a panacea. For example, filtering the herring biomass data for GB may have removed contrast in biomass and ASP needed to parameterize the model. Kalmanfiltered biomass and surplus production values for GB are restricted to the domain of the ascending limb of the production function, which is consistent with observations that the stock was heavily depressed during much of the time series we analyzed (Melvin \& Stephenson 2007). Yet, specific additional outliers need to be removed (requiring additional information beyond the scope of this study), or further recovery of the stock is needed in order to fit to the parabolic production curve of the Schaefer model. Conversely, non-stationarity in GB ecosystem processes driving surplus production may render divergent biological reference points for historical and contemporary abundances, a feature that simple production models with equilibrium assumptions are unable to capture (Walters et al. 2008). Similarly, lack of contrast and non-stationarity precluded our ability to fit production models to 4 of 13 cod stocks (i.e. WSS, NL and EBS, and to a lesser degree BALT). In particular, the data time series of population production from EBS 

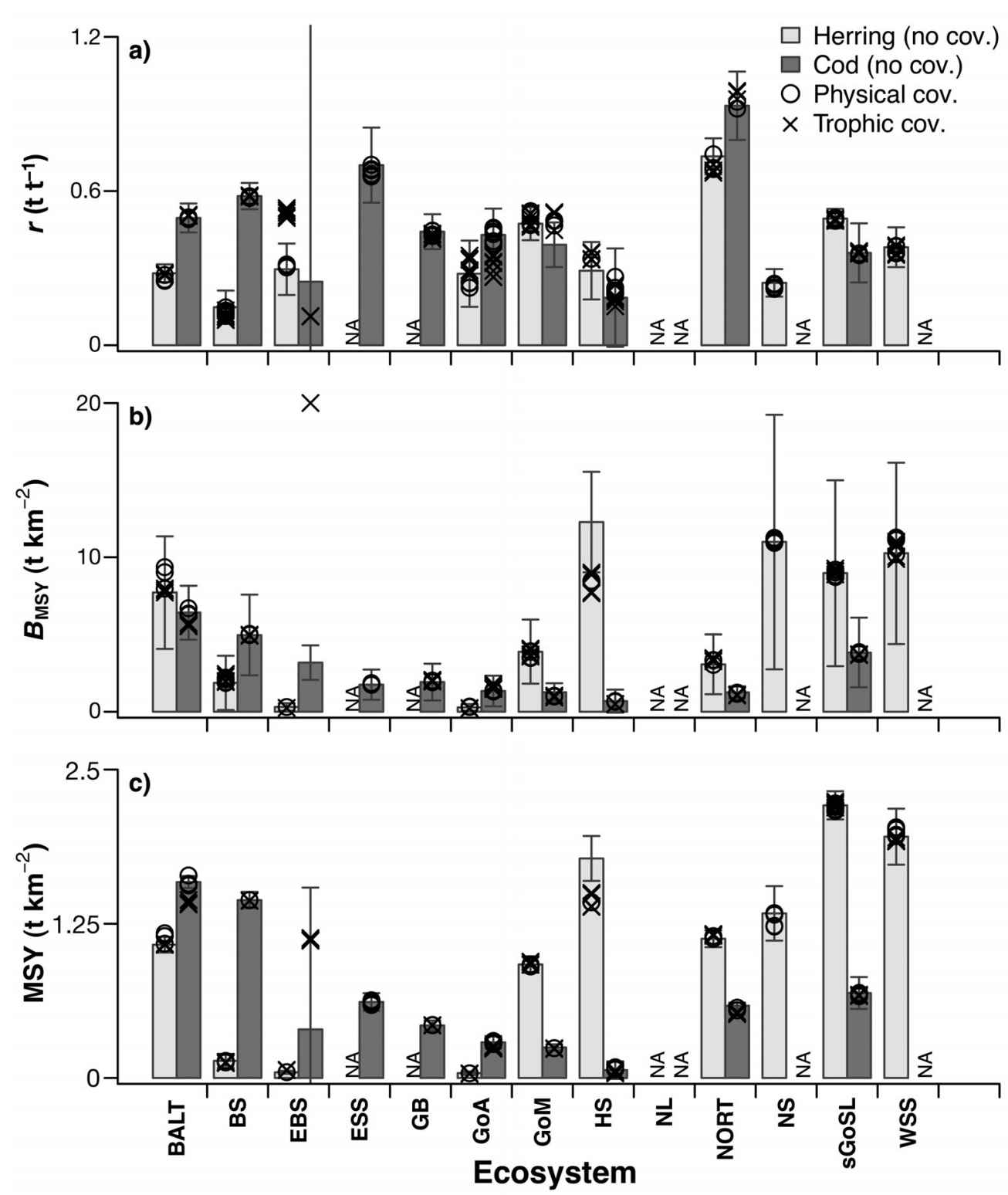

Fig. 6. Estimated values for maximum sustainable yield (MSY), biomass at MSY ( $B_{\mathrm{MSY}}$ ), and population growth rate $(r)$ for herring (light gray) and cod (dark gray) species from 13 focal ecosystems. Shaded bars: estimated values from models without covariates $( \pm 1 \mathrm{SE})$, symbols: individual model values from the top $\mathrm{AIC}_{\mathrm{c}}$ selected models with physical (O) and/or trophic covariates $(\times)$. NA: data not available. See Table 1 for ecosystem abbreviations

and NL were indicative of non-stationary production, leading to clockwise cycles of production and biomass that are not well explained by the Schaefer production model with stationary model parameters (Walters et al. 2008).

Even within the same ocean basin, variation in PDO and NAO indices are often associated with regional and species-specific changes in ecosystem structure. For example, positive PDO values are often correlated with below average ocean conditions (e.g. increased predation risk, decreased upwelling, reduced food supply; Emmett et al. 2006) in the northern Cali- fornia current and above average conditions for salmon in Alaska (Mantua et al. 1997). We also found species- and ecosystem-specific associations between ASP and atmospheric indices. Specifically, production dynamics of herring were more frequently coupled with atmospheric indices of ecosystem production than those of cod; slight changes in PDO or NAO indices were associated with measurable changes in ASP of herring species from BALT, HS and sGoSL, but only appreciably impacted estimated ASP of cod from GB (i.e. GB was the only ecosystem where average parameter confidence limits for NAO did not 
overlap zero). Similarly, biophysical covariates, particularly sea surface temperature and wind indices were more influential in models for herring species than cod species, as evidenced by mean parameter values and weights. In part, this may result from divergent life-history traits; herring are highly fecund and shorter-lived than cod and experience fluctuations in biomass that can vary by orders of magnitude with changes in environmental conditions (Nash \& Dickey-Collas 2005). In contrast, cod production integrates long-term trends in regional conditions and may lag one to many years behind ecosystem changes (e.g. Brodziak \& O'Brien 2005).

Our results also support efforts to include trophic interactions in surplus production models (i.e. Collie \& DeLong 1999, Gamble \& Link 2009); for most ecosystems, models with covariates for cod or herring biomass ranked highly with $\mathrm{AIC}_{\mathrm{c}}$ although the direction of species covariate effects was sometimes unexpected. We anticipated that cod production would be positively correlated with herring production since herring are often found in the diets of adult cod (Link \& Garrison 2002). Yet, while cod production was lower when herring biomass was also depressed in some ecosystems (i.e. BALT, BS), in others, particularly EBS, cod production was negatively correlated with herring production in the previous year. This may result from disparate juvenile cod and adult herring survival responses to environmental conditions, juvenile cod competition with herring for mutual prey resources, increased mortality from aggregation of mutual predators, or even direct predation mortality (Fauchald 2010).

Systems with strong negative correlations may also represent cultivation-depensation processes (Walters \& Kitchell 2001). According to this hypothesis, dominant predator fishes (i.e. cod) prey on forage fish species (i.e. herring), which in turn compete with larval and juvenile age classes of the predator, indirectly increasing recruitment success in subsequent years. If harvest reduces predator biomass below some critical threshold, depensation may occur as forage fish populations are released from predatory control and increasingly prey upon or compete with juvenile predators for mutual resources. We find some evidence of cultivation-depensation in 3 systems in particular (NORT, GoM, and sGoSL) and possibly GB and EBS. In these systems, herring biomass and ASP increased over time, coincident to low cod biomass and ASP that persisted even after harvest pressure on that species was reduced or eliminated. Additional analyses are needed to evaluate mechanisms driving this potentially important relationship.
The 13 systems we examined spanned a wide range of ecosystem properties from 2 ocean basins. MSY estimates did not differ by ocean basin, nor were they related to area, average depth or annual average primary production. However, MSY estimates (corrected for mean biomass for each species from each ecosystem) were related to average sea surface temperature for a number of systems, even though parameter values were not large. This suggests that large-scale climatic events (i.e. regime shifts, climate change) that induce significant warming of shallow surface waters will also be associated with changes in production of these 2 species. Our results suggest generally that herring production in these ecosystems should increase as ecosystems warm, whereas cod production should decline. Additionally, one might expect that as biophysical conditions change, populations may shift their distributions to track centers of production (Nye et al. 2009), potentially affecting spatial patterns of abundance and estimates of surplus production.

Although we found consistent evidence for the importance of including biophysical and trophodynamic covariates in production models, their inclusion did not appear to result in a consistent effect on resultant biological reference points. This finding has implications for management advice. Increasingly, analysts are asked to provide estimates of the uncertainty associated with biological reference points. Typically, biophysical and trophodynamic considerations are viewed as factors that increase observation error in input data. Our results suggest the contrary, namely that biophysical and trophodynamic covariates can be important sources of process error, and that failure to incorporate their effects can lead to underestimates of the uncertainty in biological reference points.

In summary, we found that inclusion of ecological covariates can strengthen the fit of common production models to surplus production data and help capture some of the dynamic error that is associated with highly correlated production rates observed in some ecosystems. Yet, despite similarities across the systems we examined, no single covariate was universally selected by AIC and the relative influence of an ecological covariate was system dependent, even when parameters were corrected for variability in biomass. This suggests that the potential benefit of including ecological covariates in surplus production models is species- and system-dependent, and highlights the importance of selecting biophysical and trophodynamic covariates for a region and species that have strong mechanistic underpinnings and reflect true variation in production rates. 
Acknowledgements. This collaborative, multilateral work was funded through the US Comparative Analysis of Marine Ecosystem Organization (CAMEO), the Norwegian Research Council, and Fisheries and Oceans Canada's Ecosystem Research Initiative (ERI). Major national institutes (DFO, IMR, NMFS) also contributed significant in-kind and directed resources to this project. This work is also endorsed by ESSAS. The work we report here resulted from several joint meetings, particularly the Surplus Production Modeling Workshop (SPMW 1 \& 2) and associated inter-sessional efforts, representing a continuation of and follow-on to other joint workshops, including Canadian and US Ecosystems (CANUSE I \& II), Marine Ecosystems of Norway and the US (MENU I \& II), and Norwegian-Canadian Collaborations (NORCAN). The manuscript was improved with comments from S. Gaichas, E. Buhle, K. Aydin and 3 anonymous reviewers. Finally, we dedicate this work to the memory of Bern Megrey who was an integral part of these efforts and whose untimely death was unfortunate but whose enthusiasm for this work was invaluable.

\section{LITERATURE CITED}

Baum JK, Worm B (2009) Cascading top-down effects of changing oceanic predator abundances. J Anim Ecol 78: 699-714

> Brodziak J, O'Brien L (2005) Do environmental factors affect recruits per spawner anomalies of New England groundfish? ICES J Mar Sci 62:1394-1407

Bundy A, Bohaboy EC, Hjermann DO, Mueter FJ, Fu C, Link JS (2012) Common patterns, common drivers: comparative analysis of aggregate surplus production across ecosystems. Mar Ecol Prog Ser 459:203-218

Burnham KP, Anderson DR (2002) Model selection and inference: a practical information-theoretic approach, 2nd edn. Springer, New York, NY

$>$ Carscadden JE, Frank KT, Leggett WC (2000) Evaluation of an environment-recruitment model for capelin (Mallotus villosus). ICES J Mar Sci 57:412-418

Collie JS, DeLong AK (1999) Multispecies interactions in the Georges Bank fish community. In: Ecosystem approaches for fisheries management. Alaska Sea Grant College Program, AK-SG-99-01:187-210

Collie JS, Gislason H (2001) Biological reference points for fish stocks in a multispecies context. Can J Fish Aquat Sci 58:2167-2176

Constable AJ (2011) Lessons from CCAMLR on the implementation of the ecosystem approach to managing fisheries. Fish Fish 12:138-151

> Emmett RL, Krutzikowsky GK, Bentley P (2006) Abundance and distribution of pelagic piscivorous fishes in the Columbia River plume during spring/early summer 19982003: relationship to oceanographic conditions, forage fishes, and juvenile salmonids. Prog Oceanogr 68:1-26

- Fauchald P (2010) Predator-prey reversal: a possible mechanism for ecosystem hysteresis in the North Sea? Ecology 91:2191-2197

Fu C, Gaichas S, Link JS, Bundy A and others (2012) Relative importance of fisheries, trophodynamic and environmental drivers in a series of marine ecosystems. Mar Ecol Prog Ser 459:169-184

Gaichas SK, Bundy A, Miller T, Moksness E, Stergiou KI (2012) What drives marine fisheries production? Mar Ecol Prog Ser 459:159-163
Gamble RJ, Link JS (2009) Analyzing the tradeoffs among ecological and fishing effects on an example fish community: a multispecies (fisheries) production model. Ecol Model 220:2570-2582

Hilborn R, Walters CJ (1992) Quantitative fisheries stock assessment: choice, dynamics and uncertainty. Kluwer Academic, Boston, MA

Hjort J (1914) Fluctuations in the great fisheries of northern Europe viewed in the light of biological research. Rapp P-V Reùn Cons Int Explor Mer 20:1-228

Hollowed AB, Aydin KY, Essington TE, Ianelli JN, Megrey BA, Punt AE, Smith ADM (2011) Experience with quantitative ecosystem assessment tools in the northeast Pacific. Fish Fish 12:189-208

> Hunt GL Jr, McKinnell S (2006) Interplay between top-down, bottom-up, and wasp-waist control in marine ecosystems. Prog Oceanogr 68:115-124

> Hunt GL Jr, Stabeno P, Walters G, Sinclair E, Brodeur RD, Napp JM, Bond NA (2002) Climate change and control of the southeastern Bering Sea pelagic ecosystem. DeepSea Res II 49:5821-5823

Kurlansky M (1997) Cod: a biography of the fish that changed the world. Penguin Books, New York, NY

> Leggett WC, Frank KT, Carscadden JE (1984) Meteorological and hydrographic regulation of year-class strength in capelin (Mallotus villosus). Can J Fish Aquat Sci 41:1193-1201

> Lehodey P, Alheit J, Barange M, Baumgartner T and others (2006) Climate variability, fish, and fisheries. J Clim 19:5009-5030

Link JS (2010) Ecosystem-based fisheries management: confronting tradeoffs, Cambridge University Press, Cambridge

> Link JS, Garrison LP (2002) Trophic ecology of Atlantic cod Gadus morhua on the northeast US continental shelf. Mar Ecol Prog Ser 227:109-123

> Link JS, Gaichas S, Miller TJ, Essington T and others (2012) Synthesizing lessons learned from comparing fisheries production in 13 northern hemisphere ecosystems: emergent fundamental features. Mar Ecol Prog Ser 459: 293-302

Mantua NJ, Hare SR, Zhang Y, Wallace JM, Francis RC (1997) A Pacific interdecadal climate oscillation with impacts on salmon production. Bull Am Meteorol Soc 78:1069-1079

Megrey BA, Link JS, Hunt GL Jr, Moksness E (2009) Comparative marine ecosystem analysis: applications, opportunities, and lessons learned. Prog Oceanogr 81:2-9

Melvin GD, Stephenson RL (2007) The dynamics of a recovering fish stock: Georges Bank herring. ICES J Mar Sci 64:69-82

Murawski SA, Steel J, Taylor P, Fogarty M, Sissenwine M, Ford M, Suchman C (2009) Why compare marine ecosystems? ICES J Mar Sci 67:1-9

- Myers RA (1998) When do environment-recruitment correlations work? Rev Fish Biol Fish 8:285-305

Nash RDM, Dickey-Collas M (2005) The influence of life history dynamics and environment on the determination of year class strength in North Sea herring (Clupea harengus L.). Fish Oceanogr 14:279-291

NRC (National Research Council) (1998) Improving fish stock assessments. National Academies Press, Washington, DC

Nye JA, Link JS, Hare JA, Overholtz WJ (2009) Changing spatial distribution of fish stocks in relation to climate 
and population size on the Northeast United States continental shelf. Mar Ecol Prog Ser 393:111-129

Overholtz WJ, Jacobson LD, Link JS (2008) An ecosystem approach for assessment advice and biological reference points for the Gulf of Maine-Georges Bank Atlantic herring complex. N Am J Fish Manage 28:247-257

Perry R, Schweigert J (2008) Primary productivity and the carrying capacity for herring in NE Pacific marine ecosystems. Prog Oceanogr 77:241-251

Pikitch EK, Santora C, Babcock EA, Bakun A and others (2004) Ecosystem-based fishery management. Science 305:346-347

R Development Core Team (2010) R: a language and environment for statistical computing. R Foundation for Statistical Computing, Vienna. www.R-project.org/

Schnute JT, Richards LJ (2002) Surplus production models. In: Hart PJB, Reynolds JD (eds) Handbook of fish biology and fisheries, Vol 2: Fisheries. Blackwell Science, Oxford, p 105-126

Sinclair M, Tremblay MJ (1984) Timing of spawning of Atlantic herring (Clupea harengus harengus) populations and the match-mismatch theory. Can J Fish Aquat

Submitted: October 13, 2011; Accepted: April 16, 2012
Sci 41:1055-1065

Smith AD, Brown CJ, Bulman CM, Fulton EA and others (2011) Impacts of fishing low-trophic level species on marine ecosystems. Science 333:1147-1150

Tyrrell MC, Link JS, Soustahfid H (2011) The importance of including predation in some fish population models: implications for biological reference points. Fish Res 108: $1-8$

US Commission on Ocean Policy (2004) An ocean blueprint for the 21st century. Washington, DC, available at www. oceancommission.gov

- Walters CJ, Hilborn R (2005) Exploratory assessment of historical recruitment patterns using relative abundance and catch data. Can J Fish Aquat Sci 62:1985-1990

> Walters C, Kitchell JF (2001) Cultivation/depensation effects on juvenile survival and recruitment: implications for the theory of fishing. Can J Fish Aquat Sci 58:39-50

Walters C, Martell SJD (2004) Fisheries ecology and management. Princeton University Press, Princeton, NJ

> Walters CJ, Hilborn R, Christensen V (2008) Surplus production dynamics in declining and recovering fish populations. Can J Fish Aquat Sci 65:2536-2551

Proofs received from author(s): June 19, 2012 